Public Health Genomics
Public Health Genomics 2009;12:4-10

DOI: $\underline{10.1159 / 000153430}$
Received: March 2, 2008

Accepted: May 14, 2008

Published online: September 3, 2008

\title{
Ethical, Legal, and Social Issues in Health Technology Assessment for Prenatal/ Preconceptional and Newborn Screening: A Workshop Report
}

\author{
B.K. Potter D. Avard V. Entwistle C. Kennedy P.Chakraborty M. McGuire \\ B.J. Wilson
}

Department of Epidemiology \& Community Medicine, University of Ottawa, Ottawa, Ont., Canada

\section{Key Words}

Ethical, legal, and social issues (ELSIs) • Genetic screening • Health technology assessment • Neonatal screening •

Prenatal screening $\cdot$ Public health ethics

\begin{abstract}
Prenatal/preconceptional and newborn screening programs have been a focus of recent policy debates that have included attention to ethical, legal, and social issues (ELSIs). In parallel, there has been an ongoing discussion about whether and how ELSIs may be addressed in health technology assessment (HTA). We conducted a knowledge synthesis study to explore both guidance and current practice regarding the consideration of ELSIs in HTA for prenatal/preconceptional and newborn screening. As the concluding activity for this project, we held a Canadian workshop to discuss the issues with a diverse group of stakeholders. Based on key workshop themes integrated with our study results, we suggest that population-based genetic screening programs may present particular types of ELSIs and that a public health ethics perspective is potentially highly relevant when considering them. We also suggest that approaches to addressing ELSIs in HTA for prenatal/preconceptional and newborn screening may need to be flexible enough to respond to diversity in HTA organizations, cultural values, stakeholder communities, and contextual factors. Finally, we highlight a
\end{abstract}

need for transparency in the way that HTA producers move from evidence to conclusions and the ways in which screening policy decisions are made. Copyright $\odot 2008$ S. Karger AG, Basel

\section{Background}

In June 2007, a Canadian workshop was held to discuss ethical, legal, and social issues (ELSIs) in health technology assessment (HTA) for prenatal/preconceptional and newborn genetic screening. The workshop formed the concluding activity in a larger project. Following a brief description of the background to the workshop, including the larger project, we summarize the workshop conclusions and their implications for research and practice.

Genetic Screening: Ethical, Legal, and Social Issues

Genetic screening is distinguished from genetic testing by the notion that it is offered to all members of a population or population sub-group by the health care or public health system, rather than being provided to individuals who have specifically sought clinical care or advice. Screening is considered to be genetic on the basis of its purpose to identify heritable or genetic conditions, rather than on the basis of the specific specimen tested

\section{KARGER \\ Fax +41613061234 E-Mail karger@karger.ch} www.karger.com

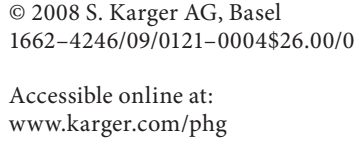

Beth K. Potter, PhD

Department of Epidemiology \& Community Medicine, University of Ottawa 451 Smyth Rd.

Ottawa ON K1H 8 M5 (Canada)

Tel. +1 613562 5800, ext. 8718, Fax +1 613562 5465, E-Mail bpotter@uottawa.ca 
(e.g., chromosomes, DNA, gene products) $[1,2]$. A number of ELSIs have been identified as being particularly important to genetic screening policy decisions [1]. These include, for example, models of consent or informed choice, education and counseling, privacy, discrimination, and the need to consider the interests of family members and other relevant stakeholder communities [e.g., 1, 3]. Many of these issues are not in fact unique to genetic screening (e.g., non-genetic screening programs are also offered to well populations and pose challenges with respect to autonomy and privacy; medical tests for infectious disease have implications for others beyond the individual tested and raise concerns about discrimination) $[2,4,5]$. However, because genetic screening technologies are rapidly evolving and have generated considerable discussion and policy debate, they present a timely and interesting case study for exploring the issues.

\section{Prenatal/Preconceptional and Newborn Genetic Screening}

The genetic screening programs with the highest population coverage and longest history to date include those directed toward pregnant women or those planning a pregnancy and toward newborn infants. In this report, and within the broader project on which it is based, we have considered prenatal and preconceptional genetic screening programs to encompass both services that offer screening tests (typically maternal blood tests and ultrasound) to identify pregnant women whose fetuses may have a relatively high probability of being affected by chromosomal abnormalities such as Down syndrome [68], and services that offer preconceptional or prenatal blood tests to couples to determine whether they are carriers of a recessively inherited genetic condition (in the event that both partners are carriers, this would mean that in any current or future pregnancies, the fetus would have a high probability of being affected by the genetic condition) [9-11].

Population-based newborn blood spot screening is a public health screening program that aims to identify infants who are at high risk of particular health conditions (typically genetic conditions with an autosomal recessive inheritance pattern) and who would benefit from the early identification and treatment of those conditions. Newborn screening for phenylketonuria and congenital hypothyroidism has been in place for decades in most developed countries, with evidence of important clinical benefits to affected infants [12]. Newborn screening programs in many jurisdictions have recently undergone large expansions in the number of disorders screened, in part based on technological advances that have made testing for additional conditions feasible. The inclusion of conditions where the balance of benefits and harms is sometimes more highly contested has in turn led to a renewed policy debate [13-17].

ELSIs have been raised in relation to both prenatal/ preconceptional and newborn screening (see Box for examples). Central to discussion of these issues is the notion of the purpose of a screening program $[18,19]$. In contemporary terms, prenatal/preconceptional screening programs are generally presented as aiming to provide women and their partners with information that might be useful in making reproductive decisions (e.g., deciding whether to conceive, to have invasive prenatal diagnostic testing where there is a high probability that a fetus is affected with a particular condition, and/or to continue or terminate a pregnancy where a fetus is found to have a particular condition). Reducing the birth prevalence of disabilities is not a stated purpose of current prenatal screening programs, but some have argued that there is a 'tension between the goals of enhancing reproductive choice and preventing the births of children who would have disabilities' [20, p. 40], which is particularly evident when screening uptake rates are reported as a prominent part of program evaluation. ELSIs raised in relation to prenatal/preconceptional screening programs can be linked to the 2 central concerns expressed in the disability rights critique, related to moral acceptability and to the potential for misinformed decision-making within individual families [20-22]. Issues connected to the moral acceptability of prenatal screening include, for example, the potential to create further societal discrimination toward people with disabilities, of particular concern to many, given the historical context of the eugenics movement [20-24]. In terms of individual decision-making, issues raised relate to informed choice, the routinization of prenatal screening, and inequities in access to counseling and screening services [20,23-32].

Newborn screening has traditionally been viewed as having a primary purpose of providing clinical benefits to affected infants. Recently, though, in the face of relatively less decisive evidence of clinical effectiveness for expanded as compared with traditional newborn screening, the potential secondary benefits of screening, including avoidance of a 'diagnostic odyssey' and the facilitation of parental reproductive choices, have been a subject of discussion $[13,33]$. In addition to the debate about whether these secondary benefits are an appropriate basis for newborn screening, other ELSIs that have been raised include potential psychosocial harms of screening (e.g., 
false positive findings), the implications of identifying unaffected infants who are heterozygous carriers of genetic mutations, considerations of how to implement screening for conditions that differ in prevalence or genotype across population sub-groups, and the roles of various stakeholder communities in policy decisionmaking $[15,34-41]$.

\section{Box: Examples of Ethical, Legal, and Social Issues Relevant to Prenatal/Preconceptional and Newborn Screening}

(a) Psychosocial harms from false positive screening results

(b) Issues related to family communication or disclosure

(c) Ethics of screening in the absence of demonstrated clinical benefits (some new conditions within expanded newborn screening programs)

(d) Issues related to disclosure of incidental findings (e.g., carrier status in newborn screening)

(e) Ethical issues surrounding predictive screening or screening for conditions with adult onset

(f) Ethical issues regarding informed choice and/or consent procedures

(g) Information and counseling needs of patients or their families

(h) Issues related to privacy and confidentiality

(i) Right of access to available testing technologies

(j) Equity considerations (e.g., in access to screening programs or treatments)

(k) Issues related to the acceptability of pregnancy termination (prenatal screening)

(l) Issues related to discrimination with respect to individuals tested (e.g., in obtaining insurance)

(m) Societal-level discrimination associated with reduced birth prevalence of conditions (prenatal screening)

\section{Ethical, Legal, and Social Issues and Health}

Technology Assessment

HTA has been defined as '.. a multidisciplinary field of policy analysis. It studies the medical, social, ethical, and economic implications of development, diffusion, and use of health technology' [42]. Thus, by definition, HTA is a policy-oriented evaluation process that includes ELSIs within its scope; yet HTA reports in practice have tended to focus mainly on technical and clinical considerations [43-45], presumably leaving ELSIs to be considered at a later stage in policy decision-making. It has been suggested that ELSIs should be directly integrated into HTA, based on 3 main arguments. First, HTA reports that incorporate ELSIs may be more useful to policymakers who wish to consider these issues in their decision-making [46, 47]. Second, addressing ELSIs in HTA may help to ensure that they are indeed appropriately considered in policy decisions [44-49]. Finally, it has been argued that treating clinical issues and ELSIs as separate considerations is an artificial distinction $[49,50]$ : a health intervention is part of a 'sociotechnical network' of people and other technologies, and it both reflects and influences values throughout its career [51, p. 50]. Despite an emerging consensus that addressing ELSIs in HTA is important, doing so poses a number of conceptual and methodological questions regarding the nature of ELSI 'evidence', how it might be identified and summarized, and whether and how it can be integrated with clinical evidence.

This discussion may be particularly relevant in areas where ELSIs have been an important focus of policy debates such as prenatal/preconceptional and newborn screening. While some of the ELSIs listed in the Box (e.g., addressing the need for counseling services) might arguably be handled at a later stage of policy decision-making, others relate to defining the very purpose of a technology (e.g., primarily for information or for clinical benefits) or may be fundamental to assessing its benefits and harms (e.g., psychosocial harms from false positive results); these latter issues may be most important for HTA.

\section{Overview of the Larger Project and Our Main \\ Findings}

The workshop followed from a larger study that was designed to look at both guidance and current practice in approaches to incorporating ELSIs in HTA, for genetic screening generally and for prenatal/preconceptional and newborn screening in particular. Our study included 3 knowledge synthesis components. First, an environmental scan was used to integrate discussions in the HTA literature with existing frameworks for policy evaluation in the fields of screening and genetic testing, in order to summarize guidance regarding the consideration of ELSIs in HTA with relevance to genetic screening. Second, a literature scan was used to identify the particular ELSIs that have been raised in connection with prenatal/preconceptional and newborn genetic screening. Finally, a systematic review was used to explore how ELSIs have been addressed within actual published HTA reports on prenatal/preconceptional and newborn screening (reports from these project components are in preparation or under review). 
Collectively, our study findings led us to conclude that ELSIs are recognized as important to policy decisions in prenatal/preconceptional and newborn screening and that the HTA, genetics, and screening communities seem to agree that ELSIs should be considered in HTA. However, specific guidance for doing so is not well-developed. While published HTA reports on these topics have tended to mention ELSIs, they have included little documentation of how ELSIs are identified or reviewed. We concluded that there was a need for greater transparency in the approaches to considering ELSIs in HTA and screening policy decisions as well as the development of appropriate methods to evaluate the approaches used to address ELSIs in HTA.

\section{Workshop Objectives and Format}

The perspectives of stakeholder communities are implicitly or explicitly embedded in genetic screening policy decisions, given that such decisions necessitate social value judgments. Thus, to aid in interpreting our study findings and to identify directions for further research and for practice, we wished to directly involve individuals from diverse stakeholder communities in a discussion of ELSIs in HTA for prenatal/preconceptional and newborn genetic screening. The objectives of our stakeholder workshop were to: ings;

(a) present our project methods and preliminary find-

(b) review other current initiatives in the areas of ethics and HTA and the evaluation of population-based genetic screening programs;

(c) gain critical feedback on our work from various stakeholders;

(d) begin to develop recommendations for HTA practice and research in the areas of prenatal/preconceptional and newborn screening.

The 28 workshop participants included HTA producers, policy decision-makers or advisors at the provincial and federal level, representatives from disease-specific consumer/family/patient organizations, health professionals, and researchers. We began the workshop with a series of 6 presentations, which included a presentation of our project findings as well as presentations from invited speakers who included HTA producers and researchers with expertise in the areas of ethics in HTA and/or genetic screening policy evaluation. Following the presentations, participants discussed and debated the issues surrounding approaches to integrating ELSIs in
HTA for prenatal/preconceptional and newborn screening, both as a full group and in heterogeneous break-out groups. The full workshop report, including summaries of the presentations, is available from the authors upon request. Here we summarize the key themes and directions that emerged from the discussions.

\section{Results: Key Themes Discussed}

The discussion at the workshop can be summarized within 5 key themes that capture many of the important issues raised:

(1) Population-based prenatal/preconceptional and newborn screening programs raise particular ELSIs that may distinguish them from other genetics health services.

Some participants emphasized that screening programs that apply to entire populations may have a unique moral significance that requires a consideration of public health ethics in HTA, in addition to the traditional focus on research and clinical ethics. Participants noted that issues related to incidental findings, disclosure of carrier status, and equity in access to care are particularly important in prenatal/preconceptional and newborn screening, yet there is little research on how to integrate public health ethics into policy evaluations. A traditional narrowly-cast 'harm-benefit' paradigm in HTA may be inadequate for the consideration of broader societal-level ELSIs (for example, related to discrimination and distributive justice) and human rights issues. Also related to the specific ELSIs of relevance, some participants felt that for newborn screening in particular, the potential harms of screening may be overemphasized in the existing academic ELSIs literature, and that there is a need in evaluations to distinguish between theoretical harms and those that have been empirically demonstrated.

(2) There is ongoing debate about the scope of HTA in relation to ELSIs and health policy.

While some participants felt that ELSIs can be considered separately from 'traditional' HTA issues in evaluating technologies to inform health policy decisions, most agreed that ELSIs should be considered within HTA. The scope of this consideration was a topic of debate, however. For example, there is a need to further discuss the extent to which HTAs should make normative recommendations about ELSIs; some participants felt that where there is no consensus on how to handle a particular issue, it is beyond the scope of the HTA producer to provide specific policy guidance. Similarly, the role that ELSIs play in contributing to the conclusions and recom- 
mendations of HTA reports about screening technologies is unclear; there is a perception that ELSIs may often be identified and mentioned but not incorporated into the overall conclusions. Finally, the scope of technologies themselves is an important consideration with respect to ELSIs in HTA; participants highlighted the need to think about screening programs in the context of an entire system of care (including ancillary services such as education, counseling, and treatment) rather than as an isolated test. Technologies may also be dynamic in terms of their use and HTA producers may need to broaden the scope of their analyses to anticipate potential technology 'creep' when considering ELSIs. For example, a policy decision regarding the availability of prenatal testing for fetal anomalies considered severe by most may influence later decisions about testing for conditions that are relatively less severe and where selective pregnancy termination would raise additional ethical concerns.

(3) Context is a key consideration for integrating ELSIs and making HTA meaningful for policy.

Participants identified a need for further discussion about how the context surrounding screening, including the legal context as well as existing funding structures, practice patterns, and available human resources, influence health policy decisions about whether and how to implement prenatal/preconceptional and newborn screening technologies. There is also a need to consider how these contextual factors relate to ELSIs. While clinical and technical findings in HTA may be relatively generalizable for some technologies, participants noted that ELSIs are more likely to be context-dependent. The use of policy decision-making frameworks that specifically incorporate context [52] could help to make this more explicit.

(4) Diversity in stakeholder interests and cultural values is important.

Participants identified a need to consider ELSIs from the perspectives of different stakeholder communities with an interest in prenatal/preconceptional and newborn screening: patients, families, citizens, society, industry, HTA producers, and policy decision-makers. A key challenge in both HTA and policy decisions is to find ways of balancing diverse interests, in terms of these groups, and in terms of balancing the cultural values of the majority with the needs of vulnerable populations and the views of advocacy groups. Some participants noted that stakeholder involvement may be particularly important in thinking through resource allocation decisions and may help to improve HTA quality as well as fairness in decision-making. Education will be important in developing strategies for stakeholder engagement, both for collective policy decision-making and at the point at which individuals are offered screening. This is particularly salient since decision-making about prenatal/preconceptional and newborn screening is often complicated by uncertainty about benefits and harms, which poses challenges in thinking through whether and how tests should be offered or encouraged.

(5) Transparency is important (in describing how ELSIs are identified, how they are considered, and the role they play in contributing to conclusions and recommendations in HTA).

Participants emphasized that transparency in describing the reasoning process from evidence to conclusions or recommendations in HTA is important, particularly if normative recommendations about ELSIs are made. This echoes the conclusion from our knowledge synthesis project that improved documentation within HTA of the methods for considering ELSIs will be an important way to understand whether and how ELSIs have been meaningfully addressed. Transparency in actual screening policy decisions (beyond HTA itself) is also important to clarify the roles of scientific evidence, ELSIs, and public demand, although such transparency may be challenging to implement in practice. In terms of ethical issues in screening, participants discussed how transparency in HTA might be improved, for example, by detailing the premise of an ethical assessment, the particular methods used and their results, and which ethical principles are considered at each stage.

\section{Conclusions}

This was the first Canadian workshop on the topic of ELSIs in HTA specific to genetic screening programs and specifically prenatal/preconceptional and newborn screening. The diversity of stakeholders who were included allowed for a rich discussion that complemented and enhanced our original project findings. By integrating the 5 key themes from the workshop with our study results, we have identified some important directions for further research and practice in HTA. First, many stakeholders at our workshop felt that it would be useful to consider population-based genetic screening programs as distinct from other genetics health services in terms of ELSIs, in order to highlight the potential relevance of public health as well as clinical ethics. For example, a public health ethics framework may emphasize collective welfare in addition to individual autonomy, focusing on 
issues such as discrimination, distributive justice, health disparities, and public engagement in decision-making [53-57].

Further, even within the relatively narrow topics of prenatal/preconceptional and newborn screening, our findings suggest that there is likely not one best approach to addressing ELSIs in HTA. There is diversity across HTA organizations in terms of their mandates and relationship to the health policy process. The workshop also led to discussions about diversity in cultural values, stakeholder communities, and contextual factors. Together, these ideas suggest that methods for addressing ELSIs in HTA will need to be flexible enough to respond to this diversity as well as to the unique features of particular technologies such as screening; this echoes current discussions in the HTA literature, which emphasize the relevance of multiple approaches to integrating ethical considerations [46].

Finally, an important finding in our project and at the workshop was the need for transparency about the ways in which HTA producers move from evidence to conclu- sions and the ways in which screening policy decisions are made. Not only will this facilitate methodological development in understanding the role of ELSIs in HTA, but it also complements a trend in health policy generally, which focuses on procedural justice, highlighting fairness, transparency, and stakeholder involvement in decision-making as means of addressing ethical complexity [58-61].

\section{Acknowledgements}

We thank all of the workshop participants for their insightful contributions to this discussion (a full list of participants is available in the workshop report which can be obtained through the authors); the authors take full responsibility for any errors or omissions in representing the workshop dialogue. We also thank additional co-investigators in our study for their important input, including Tim Caulfield, Ian Graham, Glenn Griener, Mark Montgomery, and George Wells. Finally, we gratefully acknowledge support from the Canadian Institutes of Health Research (CIHR) in the form of an operating grant (co-principal applicants B.J.W. and D.A.) and a post-doctoral fellowship (B.K.P.).

\section{References}

1 Nuffield Council on Bioethics: Genetic screening: a supplement to the 1993 report by the Nuffield Council on Bioethics. Available at www.nuffieldbioethics.org, 2006.

2 Secretary's Advisory Committee on Genetics, Health, and Society: U.S. system of oversight of genetic testing: a response to the charge of the Secretary of Health and Human Services. Draft report. Available at http://www4.od.nih.gov/oba/sacghs/reports/SACGHS_oversight_report.pdf, 2008.

-3 Godard B, ten Kate L, Evers-Kiebooms G, Ayme S: Population genetic screening programmes: principles, techniques, practices, and policies. Eur J Hum Genet 2003;11(suppl 2):S49-S87.

4 McNally E, Cambon-Thomsen A, Brazell C, Cassiman JJ, Kent A, Lindpaintner K, Lobato de Faria P, Niese D, Abbing HR, Solbakk JH, Tack H, Tambuyzer E, Weihrauch TR, Wendel E: 25 recommendations on the ethical, legal and social implications of genetic testing. European Commission. Available at http://ec.europa.eu/research/conferences/2004/genetic/pdf/recommendations_en. pdf, 2004.

5 Green MJ, Botkin JR: 'Genetic exceptionalism' in medicine: clarifying the differences between genetic and nongenetic tests. Ann Intern Med 2003;138:571-575.
Driscoll DA, Gross SJ: First trimester diagnosis and screening for fetal aneuploidy. Genet Med 2008;10:73-75.

7 ACOG Practice Bulletin No. 77: Screening for fetal chromosomal abnormalities. Obstet Gynecol 2007;109:217-227.

$\checkmark 8$ Summers AM, Langlois S, Wyatt P, Wilson RD: Prenatal screening for fetal aneuploidy. J Obstet Gynaecol Can 2007;29:146-179.

$\checkmark 9$ Committee on Genetics, American College of Obstetricians and Gynecologists: ACOG Committee Opinion. Number 325, December 2005. Update on carrier screening for cystic fibrosis. Obstet Gynecol 2005;106: 1465-1468.

-10 Achterbergh R, Lakeman P, Stemerding D, Moors EH, Cornel MC: Implementation of preconceptional carrier screening for cystic fibrosis and haemoglobinopathies: a sociotechnical analysis. Health Policy 2007;83: 277-286.

11 Roe AM, Shur N: From new screens to discovered genes: the successful past and promising present of single gene disorders. Am J Med Genet C Semin Med Genet 2007;145C: 77-86.

12 Pollitt RJ, Green A, McCabe CJ, Booth A, Cooper NJ, Leonard JV, Nicholl J, Nicholson P, Tunaley JR, Virdi NK: Neonatal screening for inborn errors of metabolism: cost, yield and outcome. Health Technol Assess 1997;1: $1-202$
13 Watson MS, Lloyd-Puryear MA, Mann MY, Rinaldo P, Howell RR: Newborn screening: toward a uniform screening panel and system. Genet Med 2006;8(suppl 1):1S-252S.

14 Botkin JR, Clayton EW, Fost NC, Burke W, Murray TH, Baily MA, Wilfond B, Berg A, Ross LF: Newborn screening technology: proceed with caution. Pediatrics 2006;117: 1793-1799.

15 Grosse SD, Boyle CA, Kenneson A, Khoury MJ, Wilfond BS: From public health emergency to public health service: the implications of evolving criteria for newborn screening panels. Pediatrics 2006;117:923-929.

$\checkmark 16$ Howell RR: We need expanded newborn screening. Pediatrics 2006;117:1800-1805.

17 Wilcken B: Mini-Symposium: Newborn screening for inborn errors of metabolism clinical effectiveness. J Inherit Metab Dis 2006;29:366-369.

18 Burke W, Zimmern R: Moving beyond ACCE: An Expanded Framework for Genetic Test Evaluation. A Paper for the United Kingdom Genetic Testing Network. Available at www.phgfoundation.org, 2007.

19 Burke W, Zimmern R, Kroese M: Defining purpose: a key step in genetic test evaluation. Genet Med 2007;9:675-681.

20 Parens E, Asch A: Disability rights critique of prenatal genetic testing: reflections and recommendations. Ment Retard Dev Disabil Res Rev 2003;9:40-47. 
-21 Parens E, Asch A: The disability rights critique of prenatal genetic testing. Reflections and recommendations. Hastings Cent Rep 1999;29:S1-S22.

-22 Munger KM, Gill CJ, Ormond KE, Kirschner KL: The next exclusion debate: assessing technology, ethics, and intellectual disability after the Human Genome Project. Ment Retard Dev Disabil Res Rev 2007;13:121128.

-23 Grant R, Flint K: Prenatal screening for fetal aneuploidy: a commentary by the Canadian Down Syndrome Society. J Obstet Gynaecol Can 2007;29:580-582.

24 Vassy C: From a genetic innovation to mass health programmes: the diffusion of Down's Syndrome prenatal screening and diagnostic techniques in France. Soc Sci Med 2006;63: 2041-2051.

-25 Dormandy E, Michie S, Hooper R, Marteau TM: Low uptake of prenatal screening for Down syndrome in minority ethnic groups and socially deprived groups: a reflection of women's attitudes or a failure to facilitate informed choices? Int J Epidemiol 2005;34: 346-352.

26 Green JM, Hewison J, Bekker HL, Bryant LD, Cuckle HS: Psychosocial aspects of genetic screening of pregnant women and newborns: a systematic review. Health Technol Assess 2004;8:1-109.

-27 Marteau TM, Dormandy E, Michie S: A measure of informed choice. Health Expect 2001; 4:99-108.

28 Potter BK, O’Reilly N, Etchegary H, Howley H, Graham I, Walker M, Coyle D, Chorny Y, Cappelli M, Boland I, Wilson BJ: Exploring informed choice in the context of prenatal testing: findings from a qualitative study. Health Expectations, in press.

-29 Suter SM: The routinization of prenatal testing. Am J Law Med 2002;28:233-270.

-30 van den Berg M, Timmermans DR, Ten Kate LP, van Vugt JM, van der Wal G: Are pregnant women making informed choices about prenatal screening? Genet Med 2005;7:332338.

-31 Williams C, Alderson P, Farsides B: Is nondirectiveness possible within the context of antenatal screening and testing? Soc Sci Med 2002;54:339-347.

-32 Williams C, Sandall J, Lewando-Hundt G, Heyman B, Spencer K, Grellier R: Women as moral pioneers? Experiences of first trimester antenatal screening. Soc Sci Med 2005;61: 1983-1992.

>33 Green NS, Dolan SM, Murray TH: Newborn screening: complexities in universal genetic testing. Am J Public Health 2006;96:19551959 .
34 Avard D, Kharaboyan L, Knoppers BM: Newborn screening for sickle cell disease socio-ethical implications; in McLean SAM (ed): First Do No Harm: Law, Ethics and Healthcare. Aldershot, Ashgate Publishing Ltd, 2006, pp 495-510.

35 Avard D, Vallance H, Greenberg C, Potter B: Newborn screening by tandem mass spectrometry: ethical and social issues. Can J Public Health 2007;98:284-286.

36 Comeau AM, Accurso FJ, White TB, Campbell PW 3rd, Hoffman G, Parad RB, Wilfond BS, Rosenfeld M, Sontag MK, Massie J, Farrell PM, O'Sullivan BP: Guidelines for implementation of cystic fibrosis newborn screening programs: Cystic Fibrosis Foundation workshop report. Pediatrics 2007;119:e495e518.

37 Grosse SD, Olney RS, Baily MA: The cost effectiveness of universal versus selective newborn screening for sickle cell disease in the US and the UK: a critique. Appl Health Econ Health Policy 2005;4:239-247.

-38 Gurian EA, Kinnamon DD, Henry JJ, Waisbren SE: Expanded newborn screening for biochemical disorders: the effect of a falsepositive result. Pediatrics 2006;117:19151921.

39 Potter BK, Avard D, Wilson BJ: Newborn blood spot screening in four countries: stakeholder involvement. J Public Health Policy 2008;29:121-142.

40 Waisbren SE, Albers S, Amato S, Ampola M, Brewster TG, Demmer L, Eaton RB, Greenstein R, Korson M, Larson C, Marsden D, Msall M, Naylor EW, Pueschel S, Seashore M, Shih VE, Levy HL: Effect of expanded newborn screening for biochemical genetic disorders on child outcomes and parental stress. JAMA 2003;290:2564-2572.

41 Wilfond BS, Parad RB, Fost N: Balancing benefits and risks for cystic fibrosis newborn screening: implications for policy decisions. J Pediatr 2005;147:S109-S113.

42 INAHTA: HTA resources. Definitions. Available at http://www.inahta.org/HTA/.

43 Draborg E, Gyrd-Hansen D, Poulsen PB, Horder M: International comparison of the definition and the practical application of health technology assessment. Int J Technol Assess Health Care 2005;21:89-95.

44 Lehoux P, Blume S: Technology assessment and the sociopolitics of health technologies. J Health Polit Policy Law 2000;25:10831120.

45 Lehoux P, Tailliez S, Denis JL, Hivon M: Redefining health technology assessment in Canada: diversification of products and contextualization of findings. Int J Technol Assess Health Care 2004;20:325-336.

46 Hofmann B: Toward a procedure for integrating moral issues in health technology assessment. Int J Technol Assess Health Care 2005;21:312-318.
47 Johri M, Lehoux P: The great escape? Prospects for regulating access to technology through health technology assessment. Int J Technol Assess Health Care 2003;19:179_ 193.

48 Autti-Ramo I, Makela M: Ethical evaluation in health technology assessment reports: An eclectic approach. Int $\mathrm{J}$ Technol Assess Health Care 2007;23:1-8.

49 Lehoux P, Williams-Jones B: Mapping the integration of social and ethical issues in health technology assessment. Int J Technol Assess Health Care 2007;23:9-16.

50 Grunwald A: The normative basis of (health) technology assessment and the role of ethical expertise. Poiesis Prax 2004;2:175-193.

51 Lehoux P: The problem of health technology. Policy implications for modern health care systems. New York, Routledge, 2006.

52 Andermann A, Beauchamp S, Costea I, Blancquaert I: Guiding decision-making for population-based screening: A systematic and multi-dimensional approach applicable to genetics. Montréal, Agence d'évaluation des technologies et des modes d'intervention en santé (AETMIS), 2007.

53 Childress JF, Faden RR, Gaare RD, Gostin LO, Kahn J, Bonnie RJ, Kass NE, Mastroianni AC, Moreno JD, Nieburg P: Public health ethics: mapping the terrain. J Law Med Ethics 2002;30:170-178.

54 Citrin T, Modell SM: Genomics and public health: Ethical, legal, and social issues; in: Genomics and Population Health: United States 2003. Atlanta, GA, Centers for Disease Control and Prevention, Office of Genomics and Disease Prevention, 2004.

55 Kass NE: An ethics framework for public health. Am J Public Health 2001;91:17761782.

56 Nuffield Council on Bioethics: Public health: ethical issues. Available at www.nuffield bioethics.org, 2007.

57 Upshur RE: Principles for the justification of public health intervention. Can J Public Health 2002;93:101-103.

58 Daniels N: Accountability for reasonableness. BMJ 2000;321:1300-1301.

59 Kenny N, Giacomini M: Wanted: a new ethics field for health policy analysis. Health Care Anal 2005;13:247-260.

60 NICE: Social value judgements. Principles for the development of NICE guidance. National Institute for Health and Clinical Excellence (NICE). Available at http://www. nice.org.uk/aboutnice/howwework/social valuejudgements/socialvaluejudgements.jsp.

61 Wailoo A, Anand P: The nature of procedural preferences for health-care rationing decisions. Soc Sci Med 2005;60:223-236. 